\title{
Adipose Tissue - Adequate, Accessible Regenerative Material
}

\author{
Lakshmi Kanth. Kolaparthy, Sahitya Sanivarapu, Srinivas Moogla, Rupa Sruthi Kutcham \\ Department of Periodontics, Sibar Institute of Dental Sciences, Guntur, Andhra Pradesh, India
}

The potential use of stem cell based therapies for the repair and regeneration of various tissues offers a paradigm shift that may provide alternative therapeutic solutions for a number of diseases. The use of either embryonic stem cells (ESCs) or induced pluripotent stem cells in clinical situations is limited due to cell regulations and to technical and ethical considerations involved in genetic manipulation of human ESCs, even though these cells are highly beneficial. Mesenchymal stem cells seen to be an ideal population of stem cells in particular, Adipose derived stem cells (ASCs) which can be obtained in large number and easily harvested from adipose tissue. It is ubiquitously available and has several advantages compared to other sources as easily accessible in large quantities with minimal invasive harvesting procedure, and isolation of adipose derived mesenchymal stem cells yield a high amount of stem cells which is essential for stem cell based therapies and tissue engineering. Recently, periodontal tissue regeneration using ASCs has been examined in some animal models. This method has potential in the regeneration of functional periodontal tissues because various secreted growth factors from ASCs might not only promote the regeneration of periodontal tissues but also encourage neovascularization of the damaged tissues. This review summarizes the sources, isolation and characteristics of adipose derived stem cells and its potential role in periodontal regeneration is discussed.

Keywords: Adipose tissue, Mesenchymal stem cells, Pluripotent stem cells, Periodontitis, Regeneration

\section{Introduction}

Periodontitis is an inflammatory disease of the periodontium which leads to irreversible loss of connective tissue attachment and supporting alveolar bone. These pathological alterations in the tooth supporting tissues lead to tooth loss. Several procedures like guided tissue regeneration, bone replacement grafts, root surface conditioning, growth factor application attempted to achieve periodontal regeneration but have their limitations in at-

\footnotetext{
Accepted for publication May 27, 2015, Published online November 30, 2015 Correspondence to Lakshmi Kanth. Kolaparthy

Department of Periodontics, Sibar Institute of Dental Sciences, Takkellapadu, Guntur 522509, Andhra Pradesh, India

Tel: +9441081047, Fax: +08632292139

E-mail: drkanth99@yahoo.co.in

(c) This is an open-access article distributed under the terms of the Creative Commons Attribution Non-Commercial License (http://creativecommons.org/ licenses/by-nc/4.0/), which permits unrestricted non-commercial use, distribution, and reproduction in any medium, provided the original work is properly cited.
}

taining predictable regeneration.

Recent advances in stem cell biology presented an enormous potential oppurtinity in regenerative treatments. The ability to restore the lost function to damaged tissue, beyond the normal capabilities of the body, is a highly-valued development in the biotechnological realm with far reaching implication. The goals of these regenerative treatments can be achieved through the application of stem cells.

Stem cells can be defined as primitive cells that have the capacity to differentiate into a variety of tissue types when induced. Stem cells offer the potential to restore function to damaged tissue by way of inducing the growth of new tissue which can be specialized for the function of that which was damaged $(1,2)$.

Stem cell candidates include Embryonic stem cells (ESC's), induced pluripotent stems cells (iPSC's), and post natal adult stem cells. Embryonic stem cells are obtained from eight cell blastula stage of mammal embroyos. They have extensive self renewal and expansion and have 
the potential to differentiate into any type of somatic tissue (3). iPSC's are derived from differentiated cells such as skin fibroblasts and appear to have the same potential and properties.Both ESC's \& IPSC's have the capability of auto-reproducibility and pluripotency. Inspite of their therapeutic potential, there are some limitations to their practical use like cellular regulation of teratoma formation, ethical consideration, immune concerns regarding ESC's, and difficulties with genetic manipulation with respect to iPSC's.

Inconstrast, post natal adult stem cells, are multipotent, immunocompatible, with no ethical concerns related to their use (4). Mesenchymal stem cells (MSC's) are non-hematopoietic cells of mesodermal derivation that are present in a number of post natal organs, and connective tissue and are multipotent.

Sources of MSC's are bone marrow derived stem cells (BSC's) and Adipose derived stem cells (ASC's).

The prototypical and best studied adult stem cell is the bone marrow derived mesenchymal stem cell. Under varying conditions, these cells could be forced to express products consistent with differentiation into bone, cartilage, muscle, tendon, cardiomyocytes and neurons.

But a major limitation of this approach was that the volume of bone marrow that could be harvested for any particular use was usually miniscule when compared with the number of cells necessary to regenerate the injured tissues. Other limitation is the harvesting procedures of BSC's which is a painful procedure and associated with significant morbidity $(5,6)$.

These limitations led to the exploration of alternative tissue sources and the possibility of niches containing undiscovered mesenchymal stem cells.

MSC's with similar characteristics to bone marrow derived MSC's has been isolated from trabecular bone, periosteum, synovial membrane, skeletal muscle, skin, pericytes, peripheral blood, deciduous teeth, periodontal ligament and umbilical cord (7). But low number of harvested cells and limited amount of harvested tissue limits their use. Further they require at least some degree of ex-vivo expansion or further manipulation before they are used preclinically or clinically to satisfy efficacy and safety requirements.

This led to discovery of Adipose derived stem cells (ASC's) from adipose tissue, by works performed on Rodents by Rodbell in 1964 (8).

Multipotent stem cells within adipose tissue, termed adipose derived stem cells (ASC's) are one of the most promising stem cells population identified since human adipose tissue is ubiquitous and easily obtained in large quantities with little donor site morbidity or patient discomfort.

\section{Adipose tissue}

Adipose tissue is composed mainly of fat cells organized into lobules. It is highly complex tissue consisting more than $90 \%$ of the tissue volume and a stromal vascular fraction (SVF) which includes preadipocytes, fibroblasts, vascular smooth muscle cells, endothelial cells, resident monocytes/ macrophages, lymphocytes and Adipose derived stem cells (ASC's) (9).

Adipose tissue like bone marrow, is derived from the mesenchyme and contains a supportive stroma that is easily isolated. Based on this, adipose tissue may represent a source of stem cells that could have far reaching effects on several fields.

Putative stem cell population within human lipoaspirate called as processed lipoaspirate (PLA) cells, can be isolated from adipose tissue in significant numbers and exhibits stable growth and proliferation kinetics in culture.

Like MSC's these PLA cells also differentiate in vitro toward the osteogenic, adipogenic, myogenic and chondrogenic lineages when treated with established lineage specific receptors. The multilineage differentiation capacity of PLA cells led us to speculate that a population of multipotent stem cells, comparable with MSC's can be isolated from human adipose tissue (10).

\section{Sources of adipose tissue}

Atleast 5 different types of adipose tissue exist: bone marrow, brown, mammary, mechanical and white adipose tissue. Each sources has a distinct biological function.

In bone marrow, adipose tissue sources has both a passive and active role. It occupies space no longer required for hematopoiesis and serves as an energy reservoir and cytokines source for osteogenic and hematopoietic events.

Brown adipose tissue is thermogenic, generating heat through the expression of a unique uncoupling protein that short circuits the mitochondrial ph gradient. Whereas brown adipose tissue is found around the major organs (heart, kidney, aorta, gonads) in the new born infant, it disappears as humans mature.

Mammary adipose tissue provides nutrients and energy during lactation and is regulated, in part, by pregnancy associated hormones.

Mechanical adipose depots, such as retroorbital and palmar fat pads, provide support to the eye, hand and other critical structures. 
Finally white adipose tissue saves are to store energy and provide insulation.

In humans, differences in stem cells recovery have been noted between subcutaneous white adipose tissue depots, with the greatest numbers recovered from the arms as compared with the thigh, abdomen and breast (11).

Furthermore, it is well established that differences exist with respect to preadipocytes and endothelial cell numbers between subcutaneous and omental white adipose depots in human subjects (12).

Sites of harvest - superficial abdominal region, upper arm, medial thigh, tronchateric and superficial deep abdominal depots (13). ASC's harvested from superficial abdominal region are more resistant to apoptosis than others. The density of stem cell reserves varies with in adipose tissue and is function of location, type and species.

In white adipose tissue, ASC are greater in subcutaneous depots compared with visceral fat, with highest concentration in arm adipose tissue depots and greater plasticity in ASC's isolated from inguinal adipose tissue depots (14).

\section{Isolation of ASC's}

The initial methods to isolate cells from adipose tissue were pioneered by Rodbell (8) and Rodbell \& Jones (15) in 1960's. Initially fragments of human tissue were minced by hand, however, this procedure has been simplified with the development of liposuction surgery.

During tumescent liposuction, plastic surgeons infuse the subcutaneous tissues with a saline solution containing anesthetic and/or epinephrine via a cannula and then remove both liquid and tissue under suction.

This procedure generates finely minced tissue fragments, the size of which depends on the dimensions of cannula. Indeed, adherent stromal cells with characteristics of adipocyte progenitors can be found directly in the liposuction aspiration fluid. However, when ultrasound assisted liposuction is performed, no. of cells recovered and their proliferative capacity from tissue digests is reduced. The optimal cell recovery was achieved using centrifugation speed of $1200 \mathrm{~g}$ (16).

There are several processes for cell isolation. One such is 'bag with in a bag'. Here the suctioned aspirate flows through central bag that automatically sieves the tissue while draining away the aspiration fluid. Subsequently, the trapped tissue can be washed and further manipulated.

Others methods includes - a closed, rotating controlled temperature incubator capable of collagenase digesting and separating up to one litre tissue at a time (17).
Once human fat is obtained, either through liposuction or lipectomy, it is placed in sterile, ice-filled plastic bags and sent to the laboratory. The extracted tissue is aseptically homogenized and then taken to a Biological Exposure Chamber, where the tissue is repeatedly washed with PBS (Phosphate Buffered Saline) until all visible blood and excessive fluids are eliminated, in order to leave fat as clean as possible. The washed fat is placed in a magnetic stirrer for $1 \mathrm{hr}$ at $37^{\circ} \mathrm{C}$. Afterwards, the fat undergoes enzymatic digestion, with the addition of a solution prepared with DMEM (Dulbecco's Modified Eagle Medium), type A collagenase, Fraction V BSA (Bovine Serum Albumin), penicillin, and streptomycin. After $1 \mathrm{hr}$, the digestion is interrupted with the addition of BFS (Bovine Fetal Serum).

The resultant material is centrifuged, and the floating fraction is discarded. The portion sitting at the bottom of the centrifuged tube (called Pellet), which is the one containing the so called stromal vascular fraction (SVF), is transferred to culture bottles filled with DMEM, BFS, pencillin, and streptomycin. The cells are taken to an incubator at $37^{\circ} \mathrm{C}$, under $5 \% \mathrm{CO} 2$, where they will expand. The liquid content of the bottles is changed daily, and the cells are washed with PBS, resulting in their adhesion to the plastic bottom of the bottles. After washing, the culture medium is replaced. Within a few days, cells will proliferate (expansion) and adhere to one another (confluence). At this point, stem cells will have become undifferentiated mesenchymal cells. When cells reach the desired expansion, they are treated with trypsin-EDTA (trypsinization), in order to rupture the intercellular junctions. This procedure results in a stem cell suspension, for clinical use of culture transfer (18).

Routinely, $1 \times 10^{7}$ adipose stromal/stem cells have been isolated from $300 \mathrm{ml}$ of lipoaspirate, with greater than $95 \%$ purity. In other words, the average frequency of ASCs in processed lipoaspirate is $2 \%$ of nucleated cells, and the yield of ASCs is approximately 5000 fibroblast colony forming units (CFU-F) per gram of adipose tissue, compared with estimates of approximately 100-1000 CFU-F per milliliter of bone marrow (18).

\section{Stem cell characteristics necessary for clinical application}

In order to be considered a viable candidate resource for clinical regenerative therapies, the following characteristics have been proposed as criteria for stem cells $(19,20)$ :

1. Able to be collected in abundant quantities

2. Able to be collected with a minimally invasive procedure. 
3. Able to differentiate into a variety of tissue types in a regulatable and reproducible manner

4. Able to be transplanted to either an autologous or allogenic host in a safe and effective manner.

\section{Abundance and availability}

Abundance of MSCs derived from bone marrow and dental pulp is limited. Collection of stem cells from these tissues can be painful and yield only relatively small quantities of viable cells. Incontrast adipose tissue yields 500 fold greater number of MSCs than bone marrow (20). ASC can be characterized as highly abundant relative to alternative stem cell varieties.

Collection of adipose tissue from a human subject in substantial quantities can be done with minimally invasive, low risk procedure that offers little discomfort to patients.Each lipoaspiration procedure routinely produces $100 \mathrm{ml}$ to more than $3 \mathrm{~L}$ of adipose tissue.

Adipose tissue has a density of approximately $0.9 \mathrm{~g} / \mathrm{ml}$, thus a single lipoaspiration procedure can yield between $90 \mathrm{gm}$ to $2700 \mathrm{gms}$ of raw adipose tissue (21). On an average each gram of adipose tissue yields approximately $5 \times 10^{3}$ stem cells $(20)$.

\section{Potentiality and differentiation}

ASC's have the ability to differentiate into different cell lineages resulting in osteogenesis (generation of bone tissue), chondrogenesis (cartilage tissue), myogenesis (muscle tissue) and adipogenesis (fat tissue).

ASC's have been found to possess the ability to differentiate into non-mesenchymal tissues such as neuron-like, endothelial, epithelial, hematopoetic and pancreatic cells (21).

ESC's are totipotent, a capacity to differentiate into all cell lineage and iPSC's are pluripotency, a more limited but still extensive range of potential differentiation, including endodermal, mesodermal and exodermal tissues. Adult stem cells such as ASC's were previously thought to be limited in their range of development into cell line of their origin - which is termed multipotency, which had been used to characterize these stem cells. But replaced by the term pleuripotency by its ability to mature into a variety of tissues (21).

Chondrogenic differentiation uses a technique known as micromass culture. ASC's are cultured at high density to encourage the formation of a sphere of cells. When given exposure to the correct differentiate media within this sphere, the cells differentiate to chondrocytes and secrete a cartilaginous matrix (22).

Myogenic differentiation occurs with lowest yield and reproducibility of all the cell types and forms multinucleated fibers that express myogenic markers such as myoD, myogenin and myosin heavy chains (23).

Osteogenic differentiation lead to cells which secrete mineralized matrix and also express mature osteoblast specific markers such as osteopontin, osteocalcin and CBFA-1. A traumatic calvarial defect complicated by chronic infection in a 7 year old girl was treated with autologous ASC's. Cells were implanted with bone fragments and fibrin glue placed between resorbable polymeric sheets. Treatment yielded complete bony coverage of the defect (24).

ASC's secrete angiogenic and survival factors that may support the growth of existing tissue. Reperfusion injury and cell damage associated with extremity replants or flap reconstructions can be ameliorated with autologous ASC's treatments. ASC's were shown to engraft into the host tissue with concomitant increases in capillary density and blood flow (25).

\section{Purity}

Contamination of stem cell lines with unidentified and undesired cells is another significant challenge confronting their clinical implementation.

Due to the relatively high abundance of stem cells in adipose tissue and the efficacy of isolation methods, ASCs represent a unique opportunity for establishing high purity cultures. Due to a high abundance of stem cells within an adipose tissue sample, the effect of unintended loss of stem cells resultant of purification processes is minimized.

The purity of ASCs can be determined by fluorescent microscopy, which requires significantly fewer cells than the more commonly employed purity assessment through flow cyometry (26).

\section{Culturing, large scale expansion and storage}

ASCs can be propagated in vitro with approximate doubling time has been reported to be between 2 and 4 days depending upon the origin, including age, tissue type (brown vs white adipose tissue) the methods of extraction, isolation and culture (20).

Bioreactor technology until now has principally been 3D scaffolding which is effective but costly and emerging bioreactor technologies involve the use of homogenous liquid phase culture and may provide a less expensive means of high volume expansion (27). 
Also there is diminished need for culture of ASCs due to their relatively high abundance when taken directly from tissue specimens.

Adipose tissue yields roughly $4500 \mathrm{CFU-F}$ of stem cells per millimeter of original tissue sample (in contrast, bone marrow yields as little as $100 \mathrm{CFU}-\mathrm{F}$ per milliliter). This diminishes the need for culturing in order to establish quantities sufficient for clinical application (28).

\section{Non-immunogenicity}

Unlike ESCs and iPSC, MSCs exhibit low immunogenity after allogenic transplantation (26). Imanishi et al. (23) showed that the level of inflammatory cytokines in living hearts that received allogenic transplants of MSCs as a treatment for acute myocardial infarction returned to near normal levels only seven days post transplant and remained at normal levels over the following weeks.

MSCs express fewer surface marker proteins and antigens that induce host immune response and rejection. Passaged ASCs (age-related) in contrast to newly isolated cells, express diminished numbers of surface antigens and fail to induce immune reactions when co-cultured with allogenic immune cells (28).

\section{Regeneration of Periodontal tissue with ASC's (29)}

ASC's implantation is emerging as an innovative method of periodontal tissue regeneration. Periodontal tissue regeneration represents a significant advance in periodontal therapy. However, the ability to regenerate large defects is limited by inadequate vascularization. Neovascularisation, a key process for wound healing and recovery of ischemia, plays a major role in survival of implanted cells (30).

ASC's secrete numerous growth factors that take part in angiogenesis and normal wound healing. ASC's secrete high levels of epidermal growth factors, basic fibroblast growth factor, keratinocyte growth factor, PDGF, insulin like growth factor, VEGF,TGF- BETA, hepatocyte growth factor (HGF), brain derived neutrophilic factor $(31,32)$.

Growth factors secreted from ASC's promote wound healing by inducing migration and proliferation of EC'S, increasing the vascularity of wound bed, increase vessel density, granulation tissue thickness and collagen deposition (33). HGF is considered as main angiogenic factor secreted by ASC's as its suppression impairs the angiogenic and regenerative effects (34).

Periodontal tissue regeneration with ASC's has been reported in experimental animal models. The interaction be- tween ASC's and PRP promotes tissue regeneration and neovascularization. Tobita et al studied the combination of ASC's and PRP with the later used as a cell vehicle/carrier in animal models $(35,36)$. In a study using rat periodontal tissue defect model, green fluorescent protein labeled rat ASC's were implanted with PRP and evaluated 2,4,and 8 weeks after implantation. The ASC'S differentiated into alveolar bone, cementum and PDL like structures after 8 weeks in situ (36).

In a canine model of periodontal tissue regeneration, ASC's were implanted with PRP into dental root bifurcation defects of the second, third and fourth mandibular premolars. After 4 weeks, ASC's and PRP prevented epithelial invasion into the defect area. After 8 weeks, newly formed bone was observed at the site of implantation (35).

Once platelets are activated releases multiple growth factors. MSC's express cell surface receptors specific to growth factors released by PRP. PRP might support the survival of high density MSC implants including ASC's, although the growth factors and mechanism involved are still not understood clearly. Therefore, to regenerate periodontal tissues faster, stem/progenitor cell implants can be used in combination with biomaterial scaffolds such as PRP to support tissue regeneration and prevent epithelial / gingival invasion $(37,38)$.

\section{Conclusion}

Advances in stem cell biology have yielded promising results in vitro and in vivo suggesting that future applications in regeneration may be achievable. Because large quantities of adipose derived stem cells can be harvested from adipose tissue, it might be possible for clinical use. The ability of the ASCs to differentiate into several tissues makes it particularly attractive type of adult stem cell for periodontal regeneration and tissue engineering.

The periodontal microenvironment may induce ASC to grow and differentiate into periodontal tissues and the ASCs themselves might secrete various cytokines that stimulate resident progenitor cells. Further preclinical and clinical studies are needed to determine whether ASC based therapies can fulfill expectations and can be used successfully in periodontal regeneration.

\section{Potential conflict of interest}

The authors have no conflicting financial interest.

\section{References}

1. Mimeault M, Hauke R, Batra SK. Stem cells: a revolution 
in therapeutics-recent advances in stem cell biology and their therapeutic applications in regenerative medicine and cancer therapies. Clin Pharmacol Ther 2007;82:252-264

2. Polak DJ. Regenerative medicine. Opportunities and challenges: a brief overview. J R Soc Interface 2010;7 Suppl 6:S777-S781

3. Lenoir N. Europe confronts the embryonic stem cell research challenge. Science 2000;287:1425-1427

4. Ben-David U, Benvenisty N. The tumorigenicity of human embryonic and induced pluripotent stem cells. Nat Rev Cancer 2011;11:268-277

5. Pittenger MF, Mackay AM, Beck SC, Jaiswal RK, Douglas R, Mosca JD, Moorman MA, Simonetti DW, Craig S, Marshak DR. Multilineage potential of adult human mesenchymal stem cells. Science 1999;284:143-147

6. Fukuda K. Use of adult marrow mesenchymal stem cells for regeneration of cardiomyocytes. Bone Marrow Transplant 2003;32 Suppl 1:S25-S27

7. Musina RA, Bekchanova ES, Sukhikh GT. Comparison of mesenchymal stem cells obtained from different human tissues. Bull Exp Biol Med 2005;139:504-509

8. Yoshimura K, Suga H, Eto H. Adipose-derived stem/progenitor cells: roles in adipose tissue remodeling and potential use for soft tissue augmentation. Regen Med 2009;4: 265-273

9. Zuk PA, Zhu M, Ashjian P, De Ugarte DA, Huang JI, Mizuno H, Alfonso ZC, Fraser JK, Benhaim P, Hedrick $\mathrm{MH}$. Human adipose tissue is a source of multipotent stem cells. Mol Biol Cell 2002;13:4279-4295

10. Schipper B, Marra KG, Rubin JP. Regional anatomic and age effects on cell function of human adipose-derived stem cells. Fourth Annual International Fat Applied Technology Society, October 21-24, 2006, Baton Rouge, La. Abstract.

11. Van Harmelen V, Röhrig K, Hauner H. Comparison of proliferation and differentiation capacity of human adipocyte precursor cells from the omental and subcutaneous adipose tissue depot of obese subjects. Metabolism 2004;53:632-637

12. Schipper BM, Marra KG, Zhang W, Donnenberg AD, Rubin JP. Regional anatomic and age effects on cell function of human adipose-derived stem cells. Ann Plast Surg 2008;60:538-544

13. Prunet-Marcassus B, Cousin B, Caton D, André M, Pénicaud L, Casteilla L. From heterogeneity to plasticity in adipose tissues: site-specific differences. Exp Cell Res 2006;312:727-736

14. Rodbell M. Metabolism of isolated fat cells. II. The similar effects of phospholipase C (Clostridium perfringens alpha toxin) and of insulin on glucose and amino acid metabolism. J Biol Chem 1966;241:130-139

15. Rodbell M, Jones AB. Metabolism of isolated fat cells. 3 . The similar inhibitory action of phospholipase C (Clostridium perfringens alpha toxin) and of insulin on lipolysis stimulated by lipolytic hormones and theophylline. J Biol Chem 1966;241:140-142

16. Kurita M, Matsumoto D, Shigeura T, Sato K, Gonda K, Harii K, Yoshimura K. Influences of centrifugation on cells and tissues in liposuction aspirates: optimized centrifugation for lipotransfer and cell isolation. Plast Reconstr Surg 2008;121:1033-1041; discussion 1042-1043

17. Katz AJ, Llull R, Hedrick MH, Futrell JW. Emerging approaches to the tissue engineering of fat. Clin Plast Surg 1999;26:587-603.

18. Boquest AC, Shahdadfar A, Brinchmann JE, Collas P. Isolation of stromal stem cells from human adipose tissue. Methods Mol Biol 2006;325:35-46

19. Gimble JM, Katz AJ, Bunnell BA. Adipose-derived stem cells for regenerative medicine. Circ Res 2007;100:1249-1260

20. Mizuno H. Adipose-derived stem cells for tissue repair and regeneration: ten years of research and a literature review. J Nippon Med Sch 2009;76:56-66

21. Bunnell BA, Flaat M, Gagliardi C, Patel B, Ripoll C. Adipose-derived stem cells: isolation, expansion and differentiation. Methods 2008;45:115-120

22. Huang JI, Zuk PA, Jones NF, Zhu M, Lorenz HP, Hedrick $\mathrm{MH}$, Benhaim P. Chondrogenic potential of multipotential cells from human adipose tissue. Plast Reconstr Surg 2004;113:585-594

23. Mizuno H, Zuk PA, Zhu M, Lorenz HP, Benhaim P, Hedrick MH. Myogenic differentiation by human processed lipoaspirate cells. Plast Reconstr Surg 2002;109:199-209

24. Lendeckel S, Jödicke A, Christophis P, Heidinger K, Wolff J, Fraser JK, Hedrick MH, Berthold L, Howaldt HP. Autologous stem cells (adipose) and fibrin glue used to treat widespread traumatic calvarial defects: case report. J Craniomaxillofac Surg 2004;32:370-373

25. Rehman J, Traktuev D, Li J, Merfeld-Clauss S, TemmGrove CJ, Bovenkerk JE, Pell CL, Johnstone BH, Considine RV, March KL. Secretion of angiogenic and antiapoptotic factors by human adipose stromal cells. Circulation 2004;109:1292-1298

26. Collas P. Programming differentiation potential in mesenchymal stem cells. Epigenetics 2010;5:476-482

27. King JA, Miller WM. Bioreactor development for stem cell expansion and controlled differentiation. Curr Opin Chem Biol 2007;11:394-398

28. Strem BM, Hicok KC, Zhu M, Wulur I, Alfonso Z, Schreiber RE, Fraser JK, Hedrick MH. Multipotential differentiation of adipose tissue-derived stem cells. Keio J Med 2005;54:132-141

29. Tobita M, Mizuno H. Adipose derived stem cells and periodontal tissue engineering. Oral Craniofac Tissue Eng 2011;1:315-321

30. Gurtner GC, Werner S, Barrandon Y, Longaker MT. Wound repair and regeneration. Nature 2008;453:314-321

31. Kilroy GE, Foster SJ, Wu X, Ruiz J, Sherwood S, Heifetz A, Ludlow JW, Stricker DM, Potiny S, Green P, Halvorsen YD, Cheatham B, Storms RW, Gimble JM. Cytokine profile of human adipose-derived stem cells: expression of angiogenic, hematopoietic, and pro-inflammatory factors. J Cell Physiol 2007;212:702-709

32. Rehman J, Traktuev D, Li J, Merfeld-Clauss S, TemmGrove CJ, Bovenkerk JE, Pell CL, Johnstone BH, Considine 
RV, March KL. Secretion of angiogenic and antiapoptotic factors by human adipose stromal cells. Circulation 2004; 109:1292-1298

33. Ebrahimian TG, Pouzoulet F, Squiban C, Buard V, André M, Cousin B, Gourmelon P, Benderitter M, Casteilla L, Tamarat R. Cell therapy based on adipose tissue-derived stromal cells promotes physiological and pathological wound healing. Arterioscler Thromb Vasc Biol 2009;29: 503-510

34. Cai L, Johnstone BH, Cook TG, Liang Z, Traktuev D, Cornetta K, Ingram DA, Rosen ED, March KL. Suppression of hepatocyte growth factor production impairs the ability of adipose-derived stem cells to promote ischemic tissue revascularization. Stem Cells 2007;25:3234-3243
35. Tobita M, Mizuno H. Periodontal disease and periodontal tissue regeneration. Curr Stem Cell Res Ther 2010;5: 168-174

36. Tobita M, Uysal AC, Ogawa R, Hyakusoku H, Mizuno H. Periodontal tissue regeneration with adipose-derived stem cells. Tissue Eng Part A 2008;14:945-953

37. Anitua E, Andia I, Ardanza B, Nurden P, Nurden AT. Autologous platelets as a source of proteins for healing and tissue regeneration. Thromb Haemost 2004;91:4-15

38. Whitman DH, Berry RL, Green DM. Platelet gel: an autologous alternative to fibrin glue with applications in oral and maxillofacial surgery. J Oral Maxillofac Surg 1997; 55:1294-1299 